American J. of Engineering and Applied Sciences 1 (3): 174-180, 2008

ISSN 1941-7020

(C) 2008 Science Publications

\title{
Effect of Inclination Angle on Performance Limit of a Closed-End Oscillating Heat Pipe
}

\author{
T. Hudakorn, P. Terdtoon and P. Sakulchangsatjatai \\ Department of Mechanical Engineering, Faculty of Engineering, \\ Chiang Mai University, Thailand
}

\begin{abstract}
This study presents the effect of inclination angle on the performance limit of a Closed-End Oscillating Heat Pipe (CEOHP). The study was divided into 2 corresponding parts. The first part was visual study. The CEOHP was made of Pyrex glass tube with the inner diameter of $1.0 \mathrm{~mm}$, evaporator length of $50 \mathrm{~mm}$ and had 10 meandering turns. The lengths of the condenser, adiabatic and evaporator sections were equal. The working fluid was R123 with filling ratio at $50 \%$ of total volume of the tube. It was found from the experiment that the performance limit at the horizontal orientation was the initial dry-out because the insufficient condensed liquid film was supplied the evaporator section. At the range of inclination angle of $5-90^{\circ}$, the cause of performance limit was dry-out due to the flooding phenomena at the entrance of the evaporator section. The second part was quantitative study. The CEOHPs were made of copper tubes with $0.66,1.06$ and $2.03 \mathrm{~mm}$ inner diameters. The evaporator lengths of CEOHPs were 50,100 and $150 \mathrm{~mm}$ and the number of meandering turns was 10 . For each CEOHP, the lengths of evaporator, adiabatic and condenser sections were equal. The working fluids were R123, ethanol and water at a filling ratio of $50 \%$ of total volume of the tube. The experiments were conducted at the inclination angles of $0-90^{\circ}$ with $10^{\circ}$ increments. With the controlled vapor temperature of $60 \pm 5^{\circ} \mathrm{C}$, it was found from the quantitative results that the critical heat flux decreases as the evaporator length increases and the critical heat flux increases with an increase in the inner diameter for all inclination angles. Moreover, this study establishes the correlation to predict the ratio of the critical heat flux at the inclination angle range of $10-90^{\circ}$ and that at vertical position. The Standard Deviation (STD) is $\pm 13.8 \%$.
\end{abstract}

Key words: Closed-end oscillating heat pipe, performance limit, inclination angle

\section{INTRODUCTION}

At present, computer technology competition is high. Responding to user needs, many companies are developing their technology to decreasing the size and increasing the performance of the computers and this requires excellent cooling system to remove heat accumulation. To solve this problem, cooling system is developed by using oscillating heat pipe. The Oscillating Heat Pipe (OHP) is high efficiency heat transfer device $^{[1]}$. There are three basic types of OHP. The first type is Closed-End OHP (CEOHP) which both ends are closed in each. The second type is Closed-Loop OHP (CLOHP) which both ends are connected in loop form. The third type is Closed-Loop OHP With Check Valve (CLOHPWCV) in which a check valve is installed at the loop.

In a decade ago, there were a lot of studies on the heat transfer characteristics ${ }^{[2-4]}$, the internal flow pattern phenomena $^{[5]}$ and the mathematical modeling ${ }^{[6,7]}$ of CEOHP at normal operating condition. However, the CEOHP has a limitation of heat transfer capability, the maximum heat transfer rate of CEOHP called the performance limit. There are many researches focus on the performance limit of CEOHP at vertical and horizontal orientation both by quantitative $\mathrm{e}^{[8-10]}$ and qualitative studies ${ }^{[11]}$. Thus, the objectives of this study are to identify the cause of performance limit of CEOHP at any inclination angle, to study the effect of inclination angle on performance limit and to establish the correlation to predict the critical heat flux at any aspect of orientation.

MATERIALS AND METHODS: For the visual study, the CEOHP was made of Pyrex glass tube which its geometry is shown in Table 1. The experimental setup of visual study is shown in Fig. 1. The evaporator section of CEOHP was heated by copper plate that was

Corresponding Author: T. Hudakorn, Department of Mechanical Engineering, Faculty of Engineering, Chiang Mai University, Thailand 
Table 1: Variable parameters of visual study and quantitative study

\begin{tabular}{lll}
\hline Parameters & Visual study & Quantitative study \\
\hline Evaporator length $(\mathrm{mm})$ & 50 & $50,100,150$ \\
Internal diameter $(\mathrm{mm})$ & 1.0 & $0.66,1.06,2.03$ \\
Working fluid & $\mathrm{R} 123$ & $\mathrm{R} 123$, ethanol \\
& & and water \\
Inclination angle & $0,5,10,30,50$, & $0,10,20,30,40$, \\
(degree) & 70,90 & $50,60,70,80,90$ \\
\hline
\end{tabular}

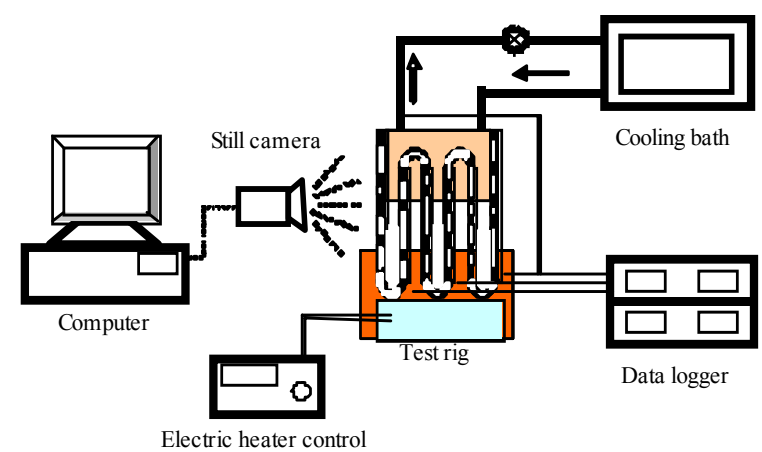

Fig. 1: Experimental setup of visual study

attached to the electric heater. The cooling water was circulated from cooling bath through the cooling jacket which was attached to the condenser section to remove the heat. The cooling water flow rate was measured by floating rotameter. Ten sets of Chromel-Alumel thermocouples (Omaga, $\mathrm{K}$ type, $\pm 0.5^{\circ} \mathrm{C}$ ) were used: four sets on the copper plate at the evaporator section for measuring the temperature, two sets at the middle of adiabatic section for measuring the vapor temperature and four sets at the inlet and the outlet of condenser section to monitor the temperature difference in order to calculate the heat transfer rate at critical state by the calorific method. Video camera (Sony DV cam, DSRPD $150 \mathrm{P}$ ) was used continuously to record the flow pattern of evaporator section, condenser section and total part of CEOHP. A still camera (Sony DSC-F 707) was used to record the internal flow pattern of evaporator section at specific times. At the beginning of experiment, the evaporator temperature was controlled at $30^{\circ} \mathrm{C}$. When the steady state was reached, the internal flow pattern, cooling water flow rate and cooling water temperatures were recorded. The procedure was repeated by increasing the evaporator temperature of $20^{\circ} \mathrm{C}$ step by step until the dry-out occurred.

The schematic diagram of the experimental setup of quantitative study is shown in Fig. 2. It consists of the CEOHP which the geometry is shown in Table 1, an $\mathrm{AC}$ high-current low-voltage power supply $(6,000 \mathrm{~A}$, $0.6 \mathrm{~V}$ ), a cooling bath, a data logger (Brainchild, VR18 and $\pm 0.5^{\circ} \mathrm{C}$ ) and a flow meter (Platon, PGB411 and $\pm 0.1 \mathrm{~L} \mathrm{~min}^{-1}$ ). Twenty-two sets of Chromel-Alumel

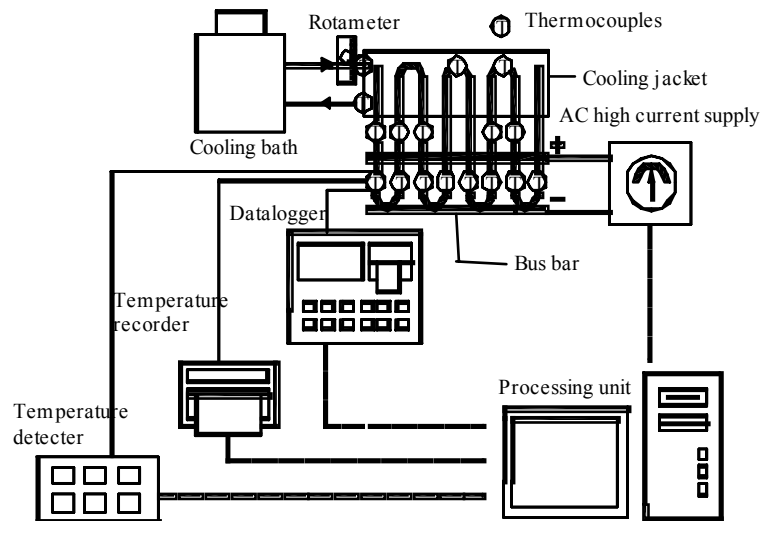

Fig. 2: Experimental setup of quantitative study

thermocouples (Omaga, $\mathrm{K}$ type, $\pm 0.5^{\circ} \mathrm{C}$ ) were placed on the CEOHP wall, i.e., ten sets in the middle of the evaporator section, four sets in middle of the adiabatic section and four sets in middle of the condenser section. Another four sets of thermocouples were used to measure the temperatures of the cooling solution, two at the inlet and two at the outlet of condenser section, in order to monitor the temperature difference. Thereafter the heat transfer at critical state was calculated by the calorific method.

\section{RESULTS AND DISCUSSION}

\section{Effect of inclination angles:}

At the inclination angle of $0-5^{\circ}$ : The visual study was done in order to find the cause of performance limit of $\mathrm{CEOHP}$ at various inclination angles. It was found that the cause of performance limit at horizontal position was initial dry-out. Before inputting heat into CEOHP, the long vapor bubbles occupied at all of the evaporator section and some of the adiabatic section. When more heat was supplied to the evaporator section, the condenser pressure did not change but the evaporator pressure increased. The liquid film in the condenser section was retarded by the vapor flow and could not be supplied to the evaporator section. The dry-out was occurred. This phenomenon is shown in Fig. 3a and b.

At the inclination angle of 5-90 ${ }^{\circ}$ : For the range of inclination angle of $5-90^{\circ}$, the cause of performance limit was dry-out at the evaporator section due to the flooding phenomena. When the evaporator temperature was increased, it was observed that the violent nucleate boiling occurred in the lower part of the CEOHP. When the vapor velocity was increased, the high-speed vapor flow retarded the returning condensate which flowed toward the evaporator section. The flooding 


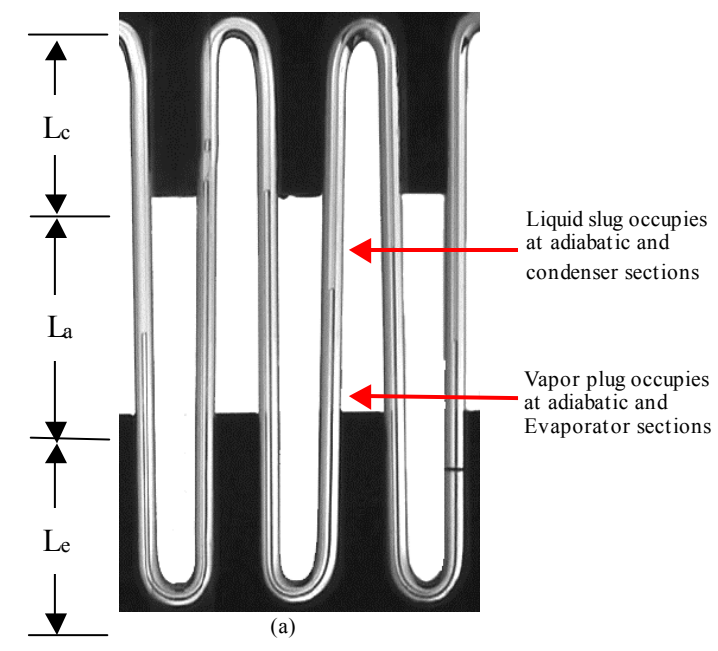

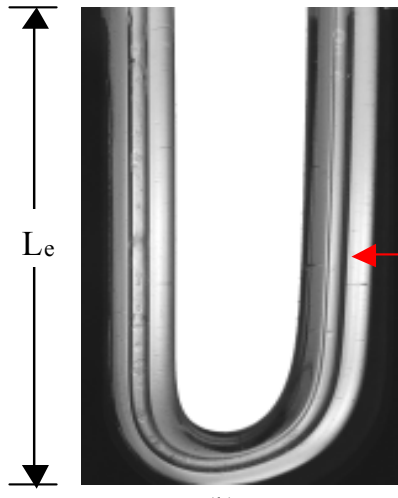

(b)

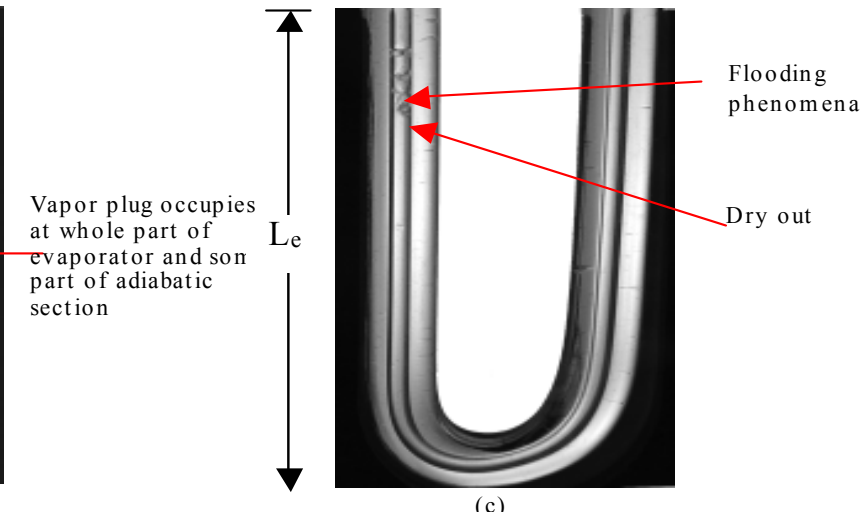

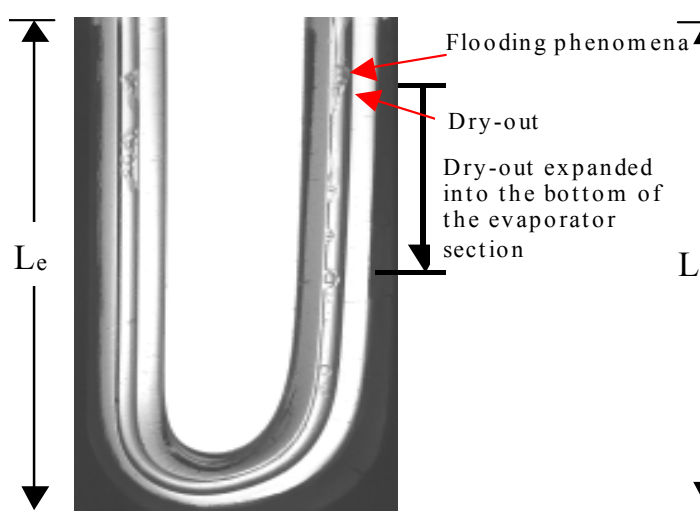

(d)

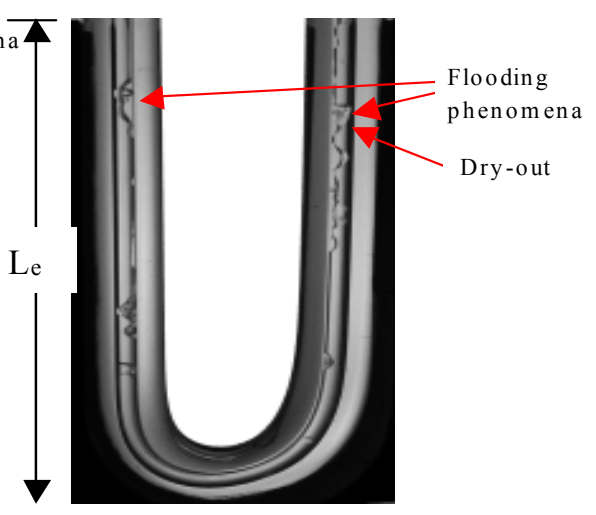

(e)

Fig. 3: The cause of performance limit of CEOHP at various inclination angles. $\left(D_{i}=1.0 \mathrm{~mm}, W F=R 123\right)$. (a): The inclination angle of $0^{\circ}$ (photo at evaporator adiabatic and condenser sections), (b): The inclination angle of $0^{\circ}$, (c): The inclination angle of $5^{\circ},(\mathrm{d})$ : The inclination angle of $70^{\circ}$ and (e): The inclination angle of $90^{\circ}$

phenomenon was observed by liquid surge at the entrance of the evaporator. Since the condensate returned to the evaporator was decreased, the liquid film thickness below the entrance was also decreased.
Intermittent dry-out, which is represented the beginning of the critical condition, occurs below the flooding region in the upper part of the evaporator section as shown in Fig. 3c-e. When heat was continuously 
Am. J. Engg. \& Applied Sci., 1 (3): 174-180, 2008

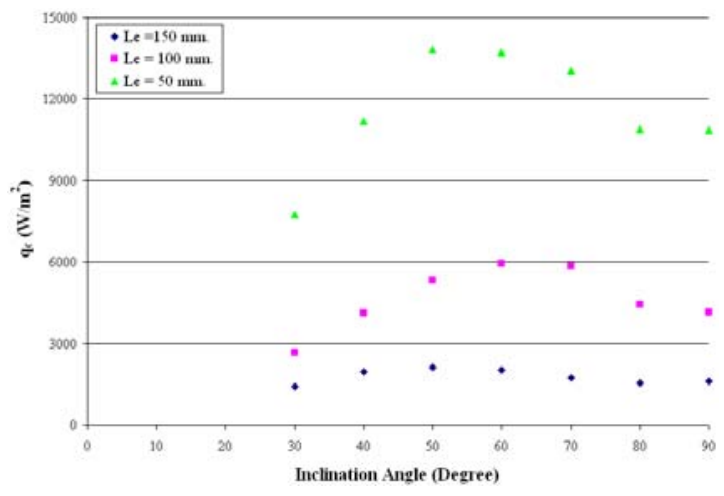

Fig. 4: Effect of inclination angle on critical heat flux at various evaporator lengths, $\left(D_{i}=1.06 \mathrm{~mm}\right.$, Turns $=10, \mathrm{R} 123$ )

supplied, the flooding phenomena occurred permanently at the upper part of the evaporator section. The dry patches expanded quickly into the bottom of the evaporator. At this condition, the heat transfer rate will steeply drop because the total thermal resistance will be immediately higher when dry-out occurs.

\section{Effect of geometries of CEOHP:}

Effect of evaporator length: In this experiment, because the evaporator and condenser lengths are of equal length, the heat fluxes at the evaporator and condenser of the CEOHP are also equal. From the quantitative experiment, as shown in Fig. 4, it is found that when the evaporator length increases, the critical heat flux decreases at every inclination angle. For example at the inclination angle of $60^{\circ}$, the evaporator length increases from $50-150 \mathrm{~mm}$ as the critical heat flux decreases from $13,724-2,032 \mathrm{~W} / \mathrm{m}^{2}$. The result of this study agrees with data from Katpradit et al..$^{[10]}$ which was found that the critical heat flux decreased as the evaporator length increased. A possible explanation is as follows: when the evaporator length increases, the vapor plug forming inside the tube is longer. The liquid film existing around the vapor bubbles will quickly evaporate toward the condenser section and retard the liquid returning from the condenser to the evaporator section. Then the amount of liquid in the evaporator section is insufficient and the dry-out occurs. Therefore the longer the evaporator length, the lower the critical heat fluxes ${ }^{[10]}$.

Effect of inner diameter: According to experimental data, as shown in Fig. 5, it can be seen that with a bigger internal diameter, the critical heat flux is higher. At the inclination angle of $70^{\circ}$, for example, the internal diameter increases from $0.66-2.03 \mathrm{~mm}$ as the critical

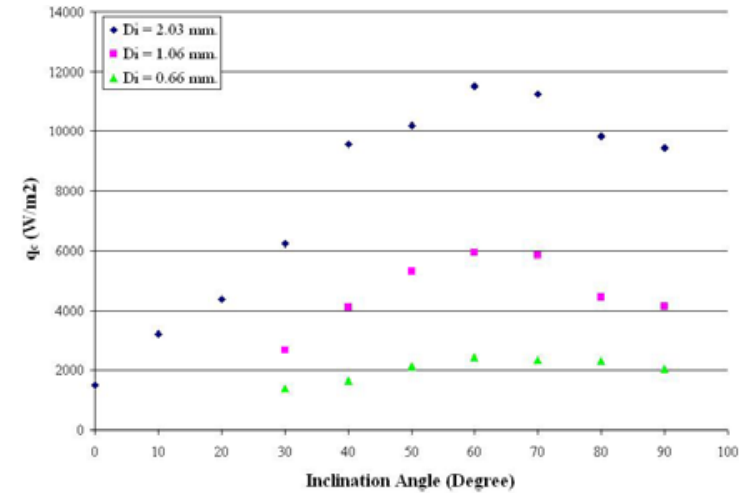

Fig. 5: Effect of inclination angle on critical heat flux at various inner diameters, $(\mathrm{Le}=100 \mathrm{~mm}$, Turns $=10, \mathrm{R} 123$ )

heat flux increases from 2,353-11,234 W/m². This data agrees with the result of Anuchitchanchai et al. ${ }^{[8]}$. A possible explanation come from the experimental result of Katpradit ${ }^{[10]}$ the vapor bubbles within the tube in a small internal diameter were longer, making a migration of vapor to the condenser section was more difficult. The liquid film at the liquid-vapor interface quickly evaporated causing a high vapor velocity and the flooding phenomena occurred easily at the top of the evaporator section. Moreover, with small diameter, vapor in the tube will tend more readily to entrain the liquid at the entrance to the evaporator ${ }^{[10]}$.

Correlation equation: From the experimental result, it was found that the geometry of tube (the evaporator length and inner diameter) affected on the heat transfer mechanism of CEOHP at critical condition. To eliminate the effect of these parameters and keep in the function form of only inclination angle, it is necessary to normalize the critical heat flux at any inclination angle with the critical heat flux at vertical position. This is achieved by considering the inclination angles and using the following equation:

$$
\frac{\mathrm{q}_{\mathrm{c}, \beta}}{\mathrm{q}_{\mathrm{c}, 90}}=\mathrm{f}(\beta)
$$

where, $f(\beta)=A \sin \beta+B \cos \beta+C$ is the function of inclination angle which can be obtained from visual study in the range of inclination angle of $5-90^{\circ}$ from horizontal position. It was found that the cause of performance limit in this range was dry-out due to the flooding phenomena at the entrance of the evaporator section. There are two main mechanisms of heat transfer at critical condition. First is the conduction heat 
transfer through the condensed liquid film flowing from the condenser to the evaporator and this film thickness is an inverse proportion to the sine function of the inclination angle ${ }^{[12]}$. Thus the heat transfer of this mechanism depends on the sine function of the inclination angle. Second is the heat transfer due to the high velocity vapor at evaporator section retards the liquid wave flowing down from condenser to form a liquid lump. The size of liquid lump increases and eventually it fills the cross section area of tube; the returning liquid is stagnant at the entrance of evaporator, as the result. The liquid film condensate can not supply the evaporator section and the critical state is reached. The vapor velocity can be determined by using the Bernoulli, conservation of mass and force balance equations of liquid lump caused by flooding phenomena at the entrance of evaporator and this velocity is the cosine function of the inclination angle. Thus, the heat transfer of this mechanism depends on the cosine function of the inclination angle.

Moreover, the results of quantitative study in the previous section showed that the geometries of CEOHP (the evaporator length and inner diameter) affected on the critical heat flux. Thus Eq. 1 should be modified by including the term of $\frac{L_{e}}{D_{i}}$, the ratio of the evaporator length and the inner diameter. It represents the dimensionless of geometry of CEOHP. The Eq. 1 can be rewritten as following:

$$
\frac{\mathrm{q}_{\mathrm{c}, \beta}}{\mathrm{q}_{\mathrm{c}, 90}}=(A \sin \beta+B \cos \beta+C)\left(\frac{\mathrm{L}_{\mathrm{e}}}{\mathrm{D}_{\mathrm{i}}}\right)^{\mathrm{X}}
$$

where, $\mathrm{X}$ is power index of aspect ratio.

By using best-fit method with experimental data of quantitative study, the constant of Eq. 2 was found. The correlation to predict the ratio of the critical heat flux at the inclination angle range of $10-90^{\circ}$ and that at vertical position was obtained as presented in Eq. 3.

$$
\frac{\mathrm{q}_{\mathrm{c}, \beta}}{\mathrm{q}_{\mathrm{c}, 90}}=(1.164 \sin \beta+0.53 \cos \beta-0.484)\left(\frac{\mathrm{L}_{\mathrm{e}}}{\mathrm{D}_{\mathrm{i}}}\right)^{0.1}
$$

It can be seen from Eq. 3 that the first term in the left-hand side of this equation is a function of inclination angle and the second term is a dimensionless of geometry of CEOHP.

Figure 6 shows the comparison of the experimental results of $q c, \beta / q_{c}, 90$ and the predicted values of $q c$, $\beta / q_{c}, 90$ from Eq. 3. It can be seen from Fig. 6 that the experimental results compared to that of Eq. 3 is in

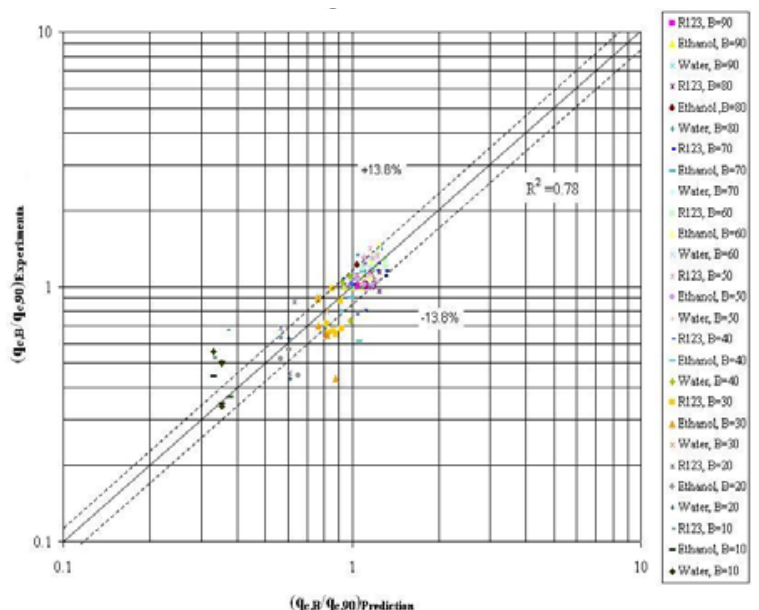

Fig. 6: Comparison between the experimental results of $\mathrm{q}_{\mathrm{c}}, \beta / \mathrm{q}_{\mathrm{c}-90}$ and the predicted values of $\mathrm{q}_{\mathrm{c}}, \beta / \mathrm{q}_{\mathrm{c}-90}$ at the range of inclination angle of $10-90^{\circ}$

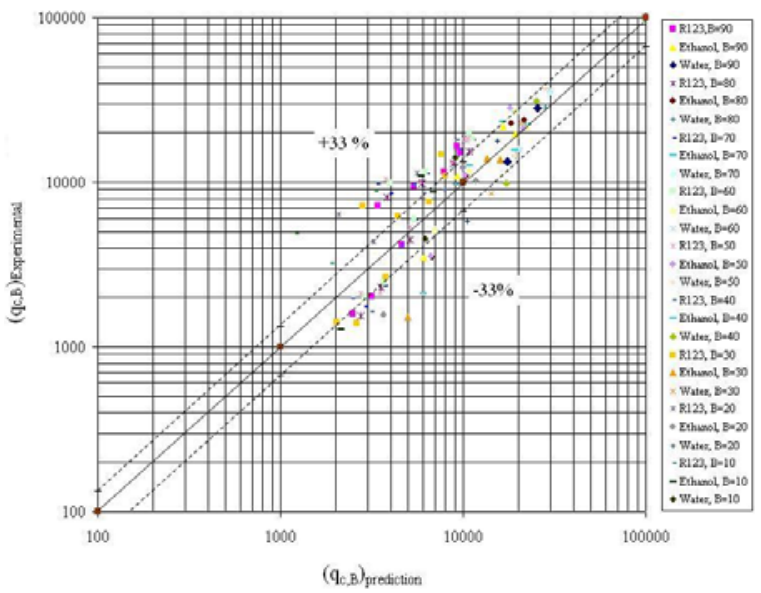

Fig. 7: Comparison between the experimental results of critical heat flux and the predicted values of critical heat flux at the range of inclination angle of $10-90^{\circ}$

good agreement. The Standard Deviation (STD) is $\pm 13.8 \%$. Thus, Eq. 3 can be generally used to predict the ratio of the critical heat flux at the range of $10-90^{\circ}$ inclination angle and that at vertical position.

To predict the critical heat flux at the range of inclination angle from $10-90^{\circ}$ by using Eq. 3 it is necessary to know the critical heat flux at vertical position evaluated from Katpradit's correlation. The experimental results and predicted values of critical heat flux at the range of inclination angle of $10-90^{\circ}$ are shown in Fig. 7. 
From Fig. 7, it is found that the Standard Deviation (STD) is $\pm 33 \%$. This standard deviation is comparatively high because of two reasons; the standard deviation of $\mathrm{q}_{\mathrm{c}}, 90$ evaluated from Katpradit's correlation and the standard deviation of Eq. 3. As seen before, the standard deviation of $\mathrm{q}_{\mathrm{c}}, 90$ is $\pm 29 \%$ and the standard deviation of Eq. 3 is $\pm 13.8 \%$. The more precision of $q_{c}, 90$, the higher precision of the predicted values of critical heat flux at the range of inclination angle of $10-90^{\circ}$ can be obtained.

\section{CONCLUSION}

A study on the effect of inclination angle on performance limit of CEOHP was conducted and it can be concluded that:

- The cause of performance limit at the horizontal orientation was the initial dry-out because the insufficient condensed liquid film was supplied the evaporator section. At the range of inclination angle of $5-90^{\circ}$, the cause of performance limit was dry-out due to the flooding phenomena at the entrance of the evaporator section

- The geometries of CEOHP are affected on the critical heat flux of CEOHP. As the evaporator length increases, the critical heat flux decreases for all inclination angles. The critical heat flux increases with an increase in the inner diameter for all inclination angles

- The correlation to predict the ratio of the critical heat flux at the inclination angle range of $10-90^{\circ}$ and that at vertical position is

$$
\frac{\mathrm{q}_{\mathrm{c}, \beta}}{\mathrm{q}_{\mathrm{c}, 90}}=(1.164 \sin \beta+0.53 \cos \beta-0.484)\left(\frac{\mathrm{L}_{\mathrm{e}}}{\mathrm{D}_{\mathrm{i}}}\right)^{0.1}
$$

and the Standard Deviation (STD) is $\pm 13.8 \%$.

\section{REFERENCES}

1. Akachi, H., F. Polasek and P. Stulc, 1996. Pulsating heat pipe. In: Proceedings of the 5th International Heat Pipe Symposium, ISBN 0-08042842-8, Nov. 17-20, Melbourne, Australia, pp: 208-216.
2. Lin, L., R. Ponnappan and J. Leland, 2000. Experimental investigation of oscillating heat pipe. In: 35th Energy Conversion Engineering Conference and Exhibit, ISBN: 1-56347-375-5, July 24-28, Nevada, USA, pp: 827-834.

3. Rittidech, S., P. Terdtoon, P. Tantakom, M. Murakami and W. Jompakdee, 2000. Effect of inclination angles, evaporator section lengths and working fluid properties on heat transfer characteristics of a closed-end oscillating heat pipe. In: Proceedings of the 6th International Heat Pipe Symposium, ISBN 974-657-448-5, Nov. 5-9, Chiang Mai Thailand, pp: 413-421.

4. Rittidech, S., P. Terdtoon, M. Murakami, P. Tantakom and W. Jompakdee, 2003. Correlation to predict heat transfer characteristics of a closedend oscillating heat pipe at normal operating condition. Applied Thermal Eng., 23: 497-510. doi:10.1016/S1359-4311(02)00215-6

5. GI, K., F. Sato and S. Maezawa, 1999. Flow visualization experiment on oscillating heat pipe. In: Proceedings of the 11th International Heat Pipe Conference, Sep. 12-16, Tokyo, Japan, pp:149-153. $\quad$ http://sciencelinks.jp/jeast/article/199918/000019991899A0624968.php

6. Sakulchangsatjatai, P., P. Kamonpet, T. Wongratanaphisan, P. Terdtoon and M. Murakami, 2003. Mathematical modeling of Closed-end and closed-loop oscillating heat pipe at normal operating condition. Applied Thermal Eng., 24: 995-1008. doi:10.1016/j.applthermaleng.2003.11.006

7. Shafii, M.A., Faghri and Y. Zhang, 2001. Thermal modeling of unlooped and looped pulsating heat pipes. J. Heat Transfer, 123: 1159-1172. http://dx.doi.org/10.1115/1.1409266

8. Anuchitchanchai, P., P. Kamonpet, T. Wongratanaphisan and P. Terdtoon, 2003. Effect of aspect ratios and internal diameter on performance limit of a closed-end oscillating heat pipe using refrigerant blend as working fluid. In: Proceedings of the 7th International Heat Pipe Symposium, ISBN 89-950046-3-093520, Oct. 1216, Jeju, Korea, pp: 243-247.

9. Katpradit, T., P. Kamonpet, T. Wongratanaphisan and P. Terdtoon, 2003. Effect of number of turns and working fluids on heat transfer characteristics of a closed-end oscillating heat pipe at critical state. In: Proceedings of the 7th International Heat Pipe Symposium, ISBN 89-950046-3093520, Oct. 12-16, Jeju, Korea, pp: 361-365. 
10. Katpradit, T., T. Wongratanaphisan, P. Terdtoon, A. Akbarzadeh and P. Kamonpet, 2005. Correlation to predict heat transfer characteristics of a closed end oscillating heat pipe at critical state. Applied Thermal Eng., 25: 2138-2151. doi:10.1016/j.applthermaleng.2005.01.009

11. Katpradit, T., T.Wongratanaphisan, P. Terdtoon, S. Ritthidech, P.Chareonsawan and S. Waowaew, 2004. Effect of Aspect Ratios and Bond Number on Internal Flow Patterns of Closed End Oscillating Heat Pipe at Critical State. In: Proceedings of the 13th International Heat Pipe Conference, ISBN 7-80144-996-7, September 2125, Shanghai, China, pp: 298-303.
12. Fiedler, S. and H. Auracher, 2004. Experimental and theoretical investigation of reflux condensation in an inclined small diameter tube. Int. J. Heat Mass Transfer, 47: 4031-4043. doi:10.1016/j.ijheatmasstransfer.2004.06.005 